\title{
Article
}

\section{Building Fluorinated Hybrid Crystals: Understanding the Role of Noncovalent Interactions}

\author{
Julen Munarriz, Federico A. Rabuffetti, and Julia Contreras-Garcia
}

Cryst. Growth Des., Just Accepted Manuscript • DOI: 10.1021/acs.cgd.8b01105 • Publication Date (Web): 26 Sep 2018

Downloaded from http://pubs.acs.org on September 27, 2018

\section{Just Accepted}

"Just Accepted" manuscripts have been peer-reviewed and accepted for publication. They are posted online prior to technical editing, formatting for publication and author proofing. The American Chemical Society provides "Just Accepted" as a service to the research community to expedite the dissemination of scientific material as soon as possible after acceptance. "Just Accepted" manuscripts appear in full in PDF format accompanied by an HTML abstract. "Just Accepted" manuscripts have been fully peer reviewed, but should not be considered the official version of record. They are citable by the Digital Object Identifier (DOI®). "Just Accepted" is an optional service offered to authors. Therefore, the "Just Accepted" Web site may not include all articles that will be published in the journal. After a manuscript is technically edited and formatted, it will be removed from the "Just Accepted" Web site and published as an ASAP article. Note that technical editing may introduce minor changes to the manuscript text and/or graphics which could affect content, and all legal disclaimers and ethical guidelines that apply to the journal pertain. ACS cannot be held responsible for errors or consequences arising from the use of information contained in these "Just Accepted" manuscripts. 


\section{INTRODUCTION}

Noncovalent chemical interactions play a key role in catalysis, biochemistry, and self-assembly of functional materials. Metalorganofluorine $(\mathrm{M} \cdots \mathrm{F}-\mathrm{C})$ is an example of donor-acceptor noncovalent interaction that determines the structure and reactivity of complexes bearing fluorinated hydrocarbon ligands. The ability of this interaction to electronically and sterically modulate the coordination sphere of metal centers belonging to $s, p, d$ and $f$ blocks has been exploited to predictively synthesize fluorinated molecules designed to serve as functional units in homogeneous catalysis, ${ }^{1-3}$ chemical vapor deposition of thin films, ${ }^{4-7}$ and bioactive compounds. ${ }^{8-10}$ Considerably less effort has been devoted to exploiting synthetic control of those interactions to design fluorinated hybrid crystals that contain multiple metal centers bridged

\begin{abstract}
Noncovalent interactions play a key role in funcional materials. Metal-organofluorine interactions are of special hybrid fluorinated materials. In-depth understanding and modulation of these interactions would enable the rational design of work, we propose a computational approach that enables a comprehensive and quantitative characterization of noncovalent interpersion-corrected density-functional theory (DFT) to Noncovalent Interactions (NCI) analysis. Additionally, we determine electron tions using a simple electrostatic model. The versatility of this approach to probe a wide range of noncovalent interactions is incorporating alkali-manganese(II) pairs and trifluoroacetato ligands. Noncovalent interactions in these hybrid crystals include Waals forces. Using $\mathrm{K}_{2} \mathrm{Mn}_{2}(\mathrm{tfa})_{6}(\mathrm{tfaH})_{2} \cdot \mathrm{H}_{2} \mathrm{O}$ as an example, we demonstrate that its two-dimensional layered structure stems from computational approach presented herein should have general applicability to the quantitative study of noncovalent interactions in hybrid crystals, thereby serving to guide crystal engineering of
\end{abstract}

by fluorinated organic ligands. Metal-fluorine contacts present in these crystals provide a low-temperature pathway for their decomposition into the corresponding mixed-metal fluorides or oxifluorides, thereby making fluorinated hybrid crystals ideal single-source precursors for solution-phase routes to compositionally complex functional materials. ${ }^{4,11-14}$

One of the main challenges facing the design and predictive synthesis of fluorinated hybrid crystals is the lack of quantitative understanding of the role of metal-fluorine noncovalent interactions in determining their crystal-chemistry. Of particular importance is the understanding of the electronic and steric effects of these interactions on metal connectivity and coordination, which ultimately dictate crystal cohesion. Packing in hybrid crystals results from a fine balance between noncovalent interactions of different nature and strength. ${ }^{15,16}$ Establishing a hierarchy of these interactions and understanding how metal-organofluorine interactions regulate their balance is therefore critical from a crystal design perspective. However, the broad range of strengths spanned by metal-organofluorine interactions limits the ability of experimental crystallography to probe their nature, strength, and compositional dependence. An archetypical and well-documented example of this limitation is the determination of metalorganofluorine contacts based on the ambiguous comparison of interatomic distances with the sum of tabulated ionic, van der Waals, or ionic van der Waals radii. ${ }^{17-20}$ Ultimately, the inability to quantitatively probe metal-halogen noncovalent interactions hinders the establishment of a set of principles guiding the design and predictive synthesis of novel organic-inorganic halogenated crystals. ${ }^{21,22}$ In the last years, different computational approaches have guided the design of new materials with improved properties by tuning noncovalent interactions. ${ }^{23-27}$ The recently developed Noncovalent Interactions (NCI) method is uniquely suited to provide a comprehensive and quantitative description of noncovalent interactions in fluorinated hybrid crystals. NCI is a topological tool enabling visualization of noncovalent interactions in real space. It is based on the analysis of the reduced gradient of the electron density $(s(\rho))^{28}$ and was originally developed to unravel weak interactions in molecular systems. ${ }^{29}$ As such, it has been used to describe a broad range of noncovalent interactions such as hydrogen $^{30,31}$ and halogen bonds. ${ }^{32,33}$ The NCI method has been extended to the study of periodic systems,${ }^{34}$ including molecular crystals, ${ }^{35,36}$ layered solids containing metallic atoms, ${ }^{37,38}$ and 
a) $\mathrm{Na}_{2} \mathrm{Mn}_{2}(\mathrm{tfa})_{6}(\mathrm{tfaH})$ b) $\mathrm{K}_{2} \mathrm{Mn}_{2}(\mathrm{tfa})_{6}(\mathrm{tfaH})_{2} \cdot \mathrm{H}_{2} \mathrm{O}$ c) $\mathrm{Rb}_{2} \mathrm{Mn}_{2}(\mathrm{tfa})_{6} \cdot \mathrm{H}_{2} \mathrm{O}$ d) $\operatorname{CsMn}(\mathrm{tfa})_{3}$
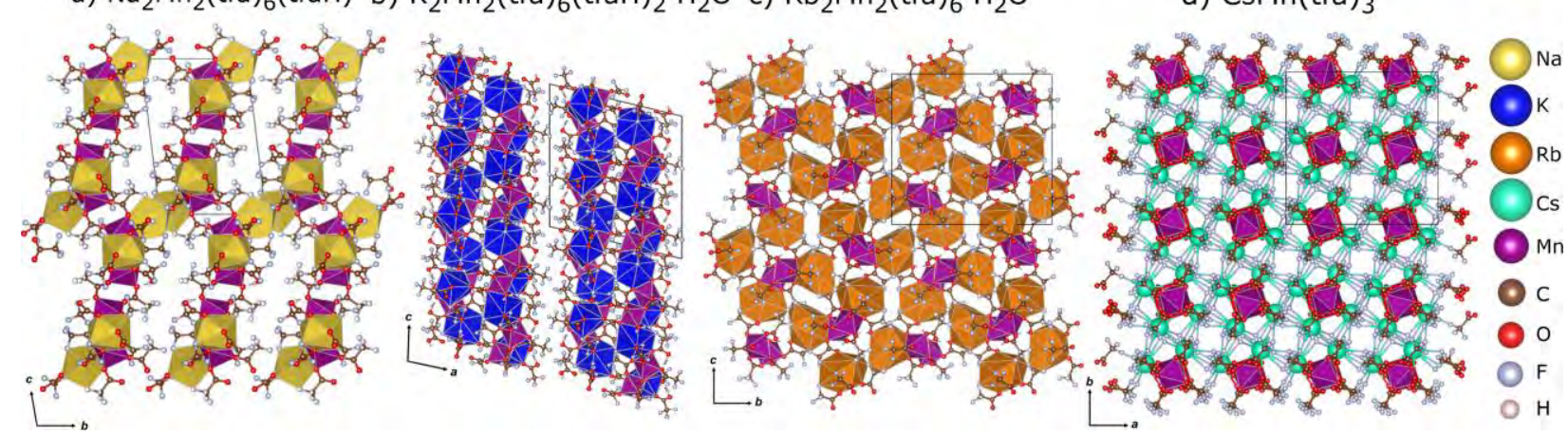

Figure 1. Crystal structures of a) $\mathrm{Na}_{2} \mathrm{Mn}_{2}(\mathrm{tfa})_{6}(\mathrm{tfaH})$ (triclinic $P \overline{1}$ space-group), b) $\mathrm{K}_{2} \mathrm{Mn}_{2}(\mathrm{tfa})_{6}(\mathrm{tfaH})_{2} \cdot \mathrm{H}_{2} \mathrm{O}$ (monoclinic $P 2_{1} / c$ spacegroup), c) $\mathrm{Rb}_{2} \mathrm{Mn}_{2}(\mathrm{tfa})_{6} \cdot \mathrm{H}_{2} \mathrm{O}$ (monoclinic $P 2_{1} / c$ space-group), and d) $\mathrm{CsMn}(\mathrm{tfa})_{3}$ (tetragonal $I 4_{1} / a$ space-group). Manganese atoms are octahedrally coordinated by oxygen while alkali atoms are coordinated by both oxygen and fluorine. $\mathrm{K}_{2} \mathrm{Mn}_{2}(\mathrm{tfa})_{6}\left(\mathrm{tfaH}_{2} \cdot \mathrm{H}_{2} \mathrm{O}\right.$ displays a distinct structure in which double layers are held together by van der Waals forces. Unit cells are depicted with solid lines.

organic-inorganic hybrid materials. ${ }^{39,40}$ The method has also proven to be suitable to aid the design novel hybrid functional materials. $^{41}$

In this article, we demonstrate that the NCI method serves to comprehensively and quantitatively map noncovalent interactions in a series of fluorinated hybrid crystals containing alkalimanganese(II) metal pairs and trifluoroacetato ligands. Bimetallic trifluoroacetates of formula $\mathrm{Na}_{2} \mathrm{Mn}_{2}(\mathrm{tfa})_{6}(\mathrm{tfaH})$, $\mathrm{K}_{2} \mathrm{Mn}_{2}(\mathrm{tfa})_{6}(\mathrm{tfaH})_{2} \cdot \mathrm{H}_{2} \mathrm{O}, \mathrm{Rb}_{2} \mathrm{Mn}_{2}(\mathrm{tfa})_{6} \cdot \mathrm{H}_{2} \mathrm{O}$, and $\mathrm{CsMn}(\mathrm{tfa})_{3}(\mathrm{tfa}$ $=$ trifluoroacetato; $\mathrm{tfaH}=$ trifluoroacetic acid) have recently been shown to serve as single-source precursors for solution-phase routes to the corresponding mixed-metal fluorides $;{ }^{14}$ their crystal structures are shown in Figure 1. Using the NCI approach, we establish the nature, strength, and compositional dependence of the four noncovalent interactions present in these hybrid crystals. These interactions are: manganese-oxygen, hydrogen bonds, alkali-oxygen, and alkali-fluorine. For the latter, their nature (i.e., electrostatic or van der Waals), strength, and spatial localization are quantitatively determined by combining NCI analysis, search of bond critical points (BCPs), and a simple point charge model. The contribution of dispersive interactions to the total crystal energy is computed for each alkali-manganese hybrid and their significance for crystal packing is discussed. Results presented in this article establish crystallochemically meaningful criteria to unravel, characterize, and tune noncovalent interactions between metal centers and fluorinated organic ligands. These criteria are expected to contribute to the design and predictive synthesis of hybrid crystals featuring organic ligands capable of establishing noncovalent interactions with metal centers.

\section{COMPUTATIONAL DETAILS}

DFT Methodology. Spin-polarized DFT calculations were performed using dispersion-corrected revPBE ${ }^{42}$ and optPBE-vdW ${ }^{43}$ functionals, both as implemented in the VASP 5.4.1 code. ${ }^{44-46}$ $\mathrm{D} 2{ }^{47}$ and $\mathrm{D} 3^{48}$ Grimme dispersion corrections, as well as D3 with Becke-Jonson damping (D3BJ), ${ }^{49}$ were added to the revPBE functional in both geometry optimizations and single point calculations. We chose these approaches due to their well-documented ability to accurately reproduce experimental parameters of a broad range of crystals (e.g., molecular, layered structures, and manganese-based materials) while keeping the computational cost reasonable. ${ }^{50-56}$ The Projector Augmented Wave (PAW) ${ }^{57,58}$ method was used to represent interactions between core and valence electrons. A plane wave cutoff of $500 \mathrm{eV}$ was used for all elements. Monkhorst-Pack k-point meshes of $5 \times 4 \times 3,2 \times 4 \times 2,5$ $\times 3 \times 3$, and $3 \times 3 \times 3$ points were employed for
$\mathrm{Na}_{2} \mathrm{Mn}_{2}(\mathrm{tfa})_{6}(\mathrm{tfaH}), \mathrm{K}_{2} \mathrm{Mn}_{2}(\mathrm{tfa})_{6}(\mathrm{tfaH})_{2} \cdot \mathrm{H}_{2} \mathrm{O}, \mathrm{Rb}_{2} \mathrm{Mn}_{2}(\mathrm{tfa})_{6} \cdot \mathrm{H}_{2} \mathrm{O}$, and $\mathrm{CsMn}(\mathrm{tfa})_{3}$, respectively.

$\mathrm{K}_{2} \mathrm{Mn}_{2}(\mathrm{tfa})_{6}(\mathrm{tfaH})_{2} \cdot \mathrm{H}_{2} \mathrm{O}$ and $\mathrm{CsMn}(\mathrm{tfa})_{3}$ exhibit layered structures held together by van der Waals forces. The cohesive energies $\left(E_{\text {cohesive }}\right)$ for these crystals were calculated as the difference between the energy of the original structure $\left(E_{\text {crystal }}\right)$ and that of the isolated layers $\left(E_{\text {layer }}\right)$, as shown in equation (1). A vacuum of $\sim 15$ $\AA$ A was included to ensure that no interlayer interactions occur.

$$
E_{\text {cohesive }}=E_{\text {crystal }}-E_{\text {layer }}
$$

Functional and Dispersion Correction Selection. Dispersioncorrected revPBE and optPBE-vdW functionals were screened prior to selecting the most suitable for the study of bimetallic trifluoroacetates. We first tested the ability of these functionals to accurately reproduce experimental lattice constants and $\mathrm{Mn} / \mathrm{K}$ $\mathrm{O} / \mathrm{F}$ distances in $\mathrm{K}_{2} \mathrm{Mn}_{2}(\mathrm{tfa})_{6}(\mathrm{tfaH})_{2} \cdot \mathrm{H}_{2} \mathrm{O}$. The relative errors for lattice constants $(\Delta)$ and the average relative error for $\mathrm{Mn} / \mathrm{K}-\mathrm{O} / \mathrm{F}$ distances $\left(\Delta_{d}\right)$ were computed using experimental crystallographic data as reference. ${ }^{14}$ The revPBE-D2 approach provided the most accurate description of the $\mathrm{K}_{2} \mathrm{Mn}_{2}(\mathrm{tfa})_{6}(\mathrm{tfaH})_{2} \cdot \mathrm{H}_{2} \mathrm{O}$ structure. A maximum error of $0.21 \%$ was obtained for lattice constants, and average errors in the $0.46-1.32 \%$ range were determined for interatomic distances. Interestingly, optPBE was the only approach that yielded negative errors for lattice constants; this likely resulted from the overestimation of dispersion forces. ${ }^{59}$ Conversely, the non-dispersion-corrected revPBE functional yielded lattice constants that were significantly larger than those observed experimentally, as well as large errors in interatomic distances. Altogether, these findings highlighted the significance of van der Waals interactions for crystal cohesion; these interactions will be described in detail later in this article. Finally, we tested the ability of the GGA $+U$ approach $^{60}$ to accurately reproduce the crystal structure of $\mathrm{K}_{2} \mathrm{Mn}_{2}(\mathrm{tfa})_{6}(\mathrm{tfaH})_{2} \cdot \mathrm{H}_{2} \mathrm{O}$. It is well-known that on-site Coulomb interactions in the localized $d$ orbitals of manganese are poorly described by the standard GGA methodology. Values of the Hubbard parameter $(U)$ between 2.0 and $5.0 \mathrm{eV}$ were employed. ${ }^{61,62}$ Structural parameters computed using the GGA $+U$ approach did not show any improvement over those obtained using standard GGA. Therefore, and considering we were primarily interested in the crystal-chemistry of fluorinated hybrids, the latter approach was utilized. The corresponding results are shown in Table $\mathbf{1}$ for all four bimetallic trifluoroacetates studied in this work. Results obtained using other approaches, including evaluation of the GGA $+U$ performance, are given in the Supporting Information (Tables S1 and S2). 
Table 1. Performance of the revPBE-D2 Methodology

Noncovalent Interactions Topological Analysis. NCI analysis enables visualization of noncovalent interactions in real space, thereby providing an intuitive representation of a broad range of attractive (e.g., van der Waals, electrostatic and hydrogen bonds) and repulsive interactions (e.g., steric clashes). This approach is based on the reduced electron density gradient $(s(\rho))$ defined in equation (2).

$$
s(\rho)=\frac{1}{2\left(3 \pi^{2}\right)^{1 / 3}} \frac{|\nabla \rho|}{\rho^{4 / 3}}
$$

Noncovalent interactions are revealed by plotting $s(\rho)$ as a function of $\operatorname{sign}\left(\lambda_{2}\right) \rho$, where the first term of the product corresponds to the sign of the second eigenvalue of the Hessian of the electron density gradient. For noninteracting systems, $s(\rho)$ behaves smoothly. By contrast, zones with low $s(\rho)$ values appear when noncovalent interactions are present. An NCI plot is informative of: (i) van der Waals interactions, which are characterized by low electron densities and $\operatorname{sign}\left(\lambda_{2}\right) \rho \approx 0$; (ii) attractive interactions, such as hydrogen bonds and strong electrostatic interactions, characterized by $\operatorname{sign}\left(\lambda_{2}\right) \rho<0$; and (iii) repulsive interactions such as steric clashes, for which $\operatorname{sign}\left(\lambda_{2}\right) \rho>0$. An intuitive representation of noncovalent interactions is obtained by plotting isosurfaces of $s(\rho)$ and coloring them according to the value of $\operatorname{sign}\left(\lambda_{2}\right) \rho$. Strong attractive interactions are depicted in blue, van der Waals in green, and steric clashes in red. Figure 2 illustrates this color coding scheme in an adenine-thymine dimer (Figure 2a), a benzene dimer (Figure 2b), and bicyclo[2.2.2] octane (Figure 2c). The shape of the isosurfaces is informative of the spatial localization of noncovalent interactions. Localized interactions such as hydrogen bonds and strong electrostatic interactions appear as blue, disc-shaped surfaces. Weak electrostatic interactions appear as green, disc-shaped surfaces. By contrast, delocalized interactions such as van der Waals interactions appear as diffuse green surfaces (see Figure 2b). In this work, NCI topological analysis $^{20}$ was employed to quantitatively probe the nature, strength, and spatial localization of manganese-oxygen, hydrogen bonds, alkali-oxygen, and alkali-fluorine noncovalent interactions occurring in $\mathrm{Na}_{2} \mathrm{Mn}_{2}(\mathrm{tfa})_{6}(\mathrm{tfaH}), \mathrm{K}_{2} \mathrm{Mn}_{2}(\mathrm{tfa})_{6}(\mathrm{tfaH})_{2} \cdot \mathrm{H}_{2} \mathrm{O}$, $\mathrm{Rb}_{2} \mathrm{Mn}_{2}(\mathrm{tfa})_{6} \cdot \mathrm{H}_{2} \mathrm{O}$, and $\mathrm{CsMn}(\mathrm{tfa})_{3}$. In addition to $\mathrm{NCI}$ analysis, we utilized the values of the electron density at Bond Critical Points (BCP, defined by $\nabla \rho=0, s(\rho)=0)$ to determine the relative strength of noncovalent interactions between a donor and a metal center. Chemical interactions were ranked using density values at $\mathrm{BCPs}^{63} \mathrm{NCI}$ calculations were performed with the critic2 software. ${ }^{64}$ VESTA was used to visualize crystal structures and their corresponding NCI plots. ${ }^{65}$

\section{RESULTS AND DISCUSSION}

Analysis of Noncovalent Interactions

Results from NCI topological analyses of interactions in $\mathrm{Na}_{2} \mathrm{Mn}_{2}(\mathrm{tfa})_{6}(\mathrm{tfaH}), \mathrm{K}_{2} \mathrm{Mn}_{2}(\mathrm{tfa})_{6}(\mathrm{tfaH})_{2} \cdot \mathrm{H}_{2} \mathrm{O}, \mathrm{Rb}_{2} \mathrm{Mn}_{2}(\mathrm{tfa})_{6} \cdot \mathrm{H}_{2} \mathrm{O}$ an $\mathrm{CsMn}(\mathrm{tfa})_{3}$ are summarized in Figure 3. This figure shows plots of the reduced density gradient as a function of $\operatorname{sign}\left(\lambda_{2}\right) \rho$. The fingerprints of four different types of noncovalent interactions can be identified in these plots; these are: manganese- a) Adenine-Thymine dimer

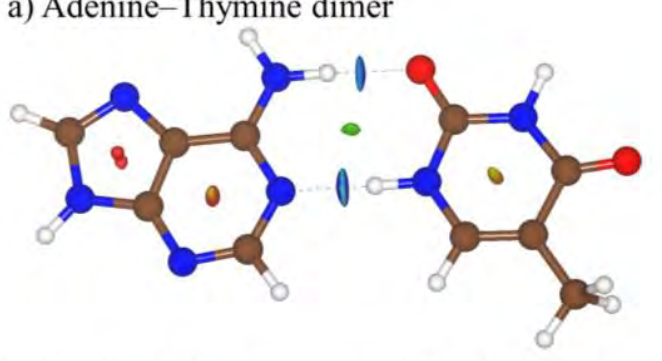

b) Benzene dimer

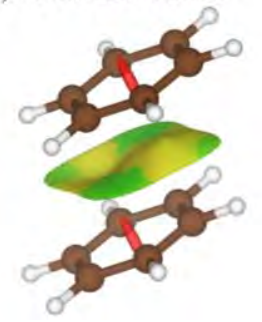

c) Bicyclo[2.2.2]octane

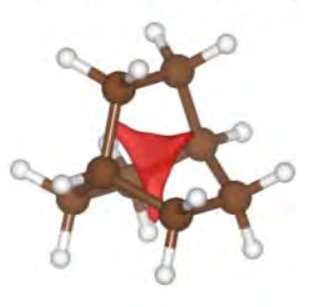

Figure 2. Three-dimensional NCI plots of a) adenine-thymine dimer (hydrogen bonds depicted in bue), b) benzene dimer (dispersive interactions depicted in green, and c) bicyclo[2.2.2] octane (steric clashes depicted in red). Surfaces are colored in the $[-0.04$, $0.04]$ a.u. range of $\operatorname{sign}\left(\lambda_{2}\right) \rho$ (isosurface $s=0.5$ a.u.).

oxygen (region A), hydrogen bonds (region B), alkali-oxygen (region $\mathrm{C}$ ), and alkali-fluorine (region D). $\operatorname{Sign}\left(\lambda_{2}\right) \rho$ average values and interatomic distance ranges for these interactions are included in Table 2.

Manganese-Oxygen Interactions. Manganese-oxygen interactions are located in region A of the NCI plots shown in Figure 3. Inspection of Figure $\mathbf{3}$ and Table 2 shows that the fingerprints of these interactions exhibit the most negative $\operatorname{sign}\left(\lambda_{2}\right) \rho$ values Thus, manganese-oxygen interactions are the strongest noncovalent interactions occurring in the compounds under study; $\mathrm{K}_{2} \mathrm{Mn}_{2}(\mathrm{tfa})_{6}(\mathrm{tfaH})_{2} \cdot \mathrm{H}_{2} \mathrm{O}$ is the only exception to this trend and will be discussed below. A representative three-dimensional NCI plot of manganese-oxygen interactions is shown in Figure 4 for $\mathrm{CsMn}(\mathrm{tfa})_{3}$; plots for other compositions are provided in the Supporting Information (Figure S1). In all cases, the reduced density gradient isosurface exhibits a well-defined disc-like shape, indicating a highly localized interaction. ${ }^{66}$ This observation, in conjunction with the values of $\operatorname{sign}\left(\lambda_{2}\right) \rho$, points towards an electrostatic interaction between manganese and oxygen atoms. Further inspection of Table 2 shows that the average values of $\operatorname{sign}\left(\lambda_{2}\right) \rho$ remain nearly constant for all the trifluoroacetates (ca. 0.055 a.u.), with the exception of $\mathrm{K}_{2} \mathrm{Mn}_{2}(\mathrm{tfa})_{6}(\mathrm{tfaH})_{2} \cdot \mathrm{H}_{2} \mathrm{O}(-0.051$ a.u.). The range of values, on the other hand, becomes narrower upon going from sodium to cesium. The compositional dependence of manganese-oxygen interactions can be rationalized by grouping them according to the nature of the oxygen donor; that is, whether it belongs to a trifluoroacetato, acuo, or protonated 


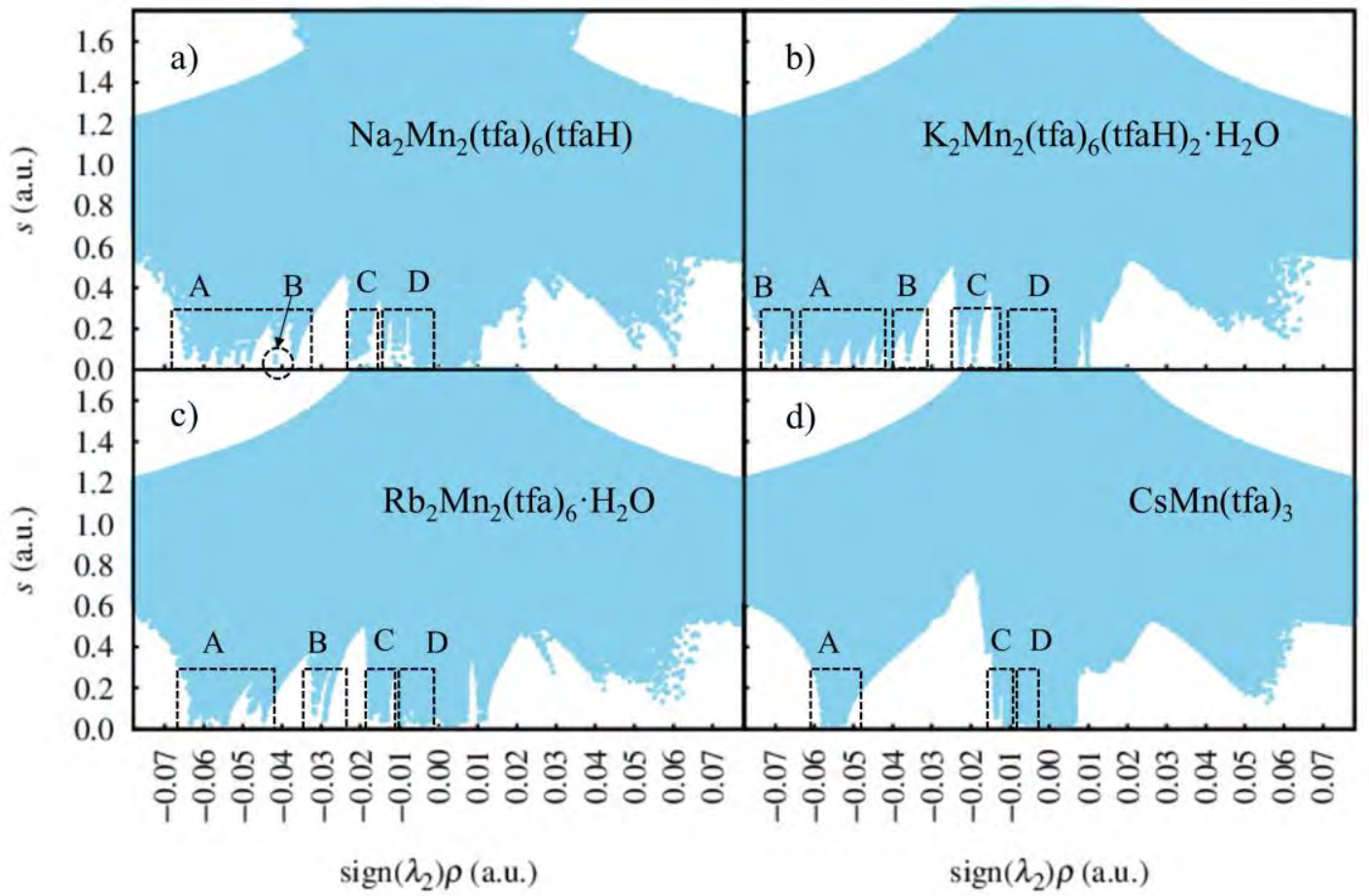

Figure 3. $\mathrm{NCI}$ plots for a) $\left.\mathrm{Na}_{2} \mathrm{Mn}_{2}(\mathrm{tfa})_{6}(\mathrm{tfaH}), \mathrm{b}\right) \mathrm{K}_{2} \mathrm{Mn}_{2}(\mathrm{tfa})_{6}(\mathrm{tfaH})_{2} \cdot \mathrm{H}_{2} \mathrm{O}$, c) $\mathrm{Rb}_{2} \mathrm{Mn}_{2}(\mathrm{tfa})_{6} \cdot \mathrm{H}_{2} \mathrm{O}$, and d) CsMn(tfa $)_{3}$. Regions A, $\mathrm{B}, \mathrm{C}$, and $\mathrm{D}$ correspond to manganese-oxygen, hydrogen bonds, alkali-oxygen, and alkali-fluorine interactions, respectively.

Table 2. $\operatorname{Sign}\left(\lambda_{2}\right) \rho$ (in a.u.) for Noncovalent Interactions in Bimetallic Trifluoroacetates

\begin{tabular}{|c|c|c|c|c|c|c|}
\hline & \multicolumn{5}{|c|}{ Manganese-Oxygen } & \multirow[b]{2}{*}{ Distance Range $(\AA)$} \\
\hline & Average & Range & $\mathrm{Mn}-\mathrm{O}(\mathrm{tfa})$ & $\mathrm{Mn}-\mathrm{O}\left(\mathrm{H}_{2} \mathrm{O}\right)$ & $\mathrm{Mn}-\mathrm{O}(\mathrm{tfaH})$ & \\
\hline $\mathrm{Na}$ & -0.055 & {$[-0.065,-0.037]$} & {$[-0.065,-0.050]$} & $\mathrm{n} / \mathrm{a}$ & -0.037 & $2.104-2.354$ \\
\hline $\mathrm{K}$ & -0.051 & {$[-0.063,-0.041]$} & {$[-0.063,-0.044]$} & -0.048 & -0.041 & $2.100-2.312$ \\
\hline $\mathrm{Rb}$ & -0.055 & {$[-0.062,-0.045]$} & {$[-0.062,-0.054]$} & {$[-0.048,-0.045]$} & $\mathrm{n} / \mathrm{a}$ & $2.107-2.283$ \\
\hline \multirow[t]{3}{*}{ Cs } & -0.055 & {$[-0.058,-0.052]$} & {$[-0.058,-0.052]$} & $\mathrm{n} / \mathrm{a}$ & $\mathrm{n} / \mathrm{a}$ & $2.157-2.187$ \\
\hline & \multicolumn{5}{|c|}{ Hydrogen Bonds } & \\
\hline & & & & $\mathrm{H}_{2} \mathrm{O}$ & $\mathrm{tfaH}$ & \\
\hline $\mathrm{Na}$ & & & & $\mathrm{n} / \mathrm{a}$ & -0.042 & \\
\hline K & & & & {$[-0.036,-0.023]$} & {$[-0.072,-0.068]$} & \\
\hline \multirow[t]{3}{*}{$\mathrm{Rb}$} & & & & {$[-0.032,-0.029]$} & $\mathrm{n} / \mathrm{a}$ & \\
\hline & \multicolumn{5}{|c|}{ Alkali-Oxygen } & \\
\hline & Average & Range & & & & Distance Range $(\AA)$ \\
\hline $\mathrm{Na}$ & -0.021 & {$[-0.022,-0.018]$} & & & & $2.293-2.456$ \\
\hline $\mathrm{K}$ & -0.012 & {$[-0.019,-0.008]$} & & & & $2.600-3.143$ \\
\hline $\mathrm{Rb}$ & -0.015 & {$[-0.017,-0.013]$} & & & & $2.831-3.127$ \\
\hline \multirow[t]{3}{*}{ Cs } & -0.011 & {$[-0.014,-0.009]$} & & & & $3.078-3.259$ \\
\hline & \multicolumn{5}{|c|}{ Alkali-Fluorine } & \\
\hline & Average & Electrostatic & Average & van der Waals & & Distance Range $(\AA)$ \\
\hline $\mathrm{Na}$ & -0.0085 & {$[-0.011,-0.006]$} & -0.003 & {$[-0.004,-0.002]$} & & $2.470-2.933$ \\
\hline K & -0.0095 & {$[-0.011,-0.008]$} & -0.004 & {$[-0.005,-0.003]$} & & $2.696-3.304$ \\
\hline $\mathrm{Rb}$ & -0.0080 & {$[-0.010,-0.006]$} & -0.003 & {$[-0.004,-0.002]$} & & $2.934-3.589$ \\
\hline Cs & -0.0055 & {$[-0.008,-0.003]$} & $\mathrm{n} / \mathrm{a}$ & $\mathrm{n} / \mathrm{a}$ & & $3.154-3.679$ \\
\hline
\end{tabular}




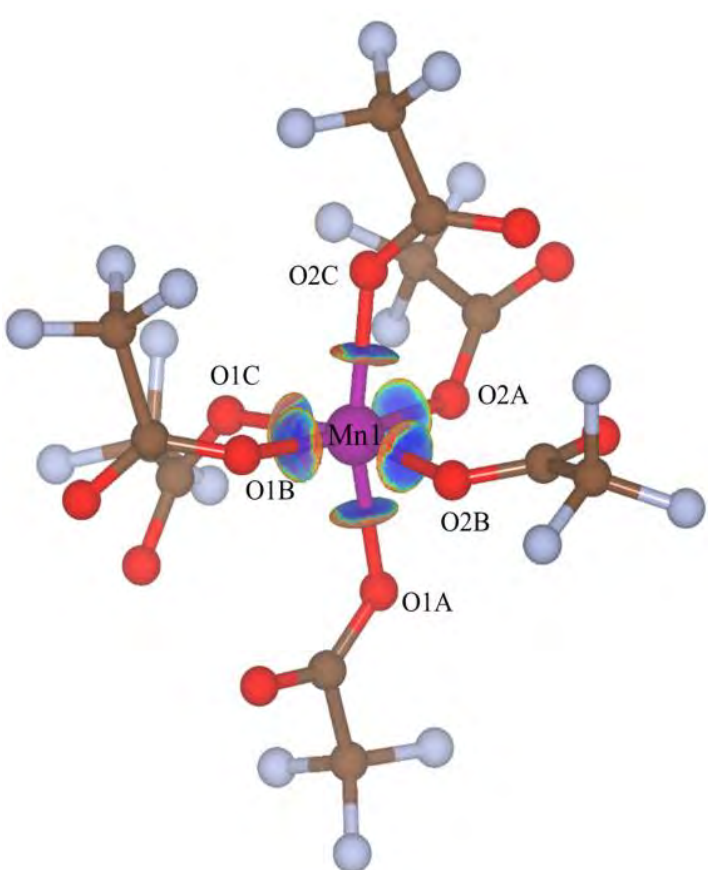

Figure 4. Three-dimensional NCI plot of manganese-oxygen interactions in $\mathrm{CsMn}(\mathrm{tfa})_{3}$. Surfaces are colored in the $[-0.07$, $0.07]$ a.u. range of $\operatorname{sign}\left(\lambda_{2}\right) \rho$ (isosurface $s=0.5$ a.u.).

trifluoroacetato ligand. Comparison of $\operatorname{sign}\left(\lambda_{2}\right) \rho$ values for each type of oxygen donor suggests that the strength of these interactions can be ranked as follows: $\mathrm{Mn}-\mathrm{O}(\mathrm{tfa})>\mathrm{Mn}-\mathrm{O}\left(\mathrm{H}_{2} \mathrm{O}\right)>\mathrm{Mn}-$ $\mathrm{O}(\mathrm{tfaH})$. This result can be understood noting that the trifluoroacetato ligand is negatively charged, whereas acuo and protonated trifluoroacetato ligands are neutral. The trifluoroacetato ligand is therefore expected to be more nucleophilic and its interaction with manganese stronger. Interactions established between manganese and oxygen donors belonging to the negatively charged trifluoroacetato ligand appear in the same $\operatorname{sign}\left(\lambda_{2}\right) \rho$ range, indicating that their strength is comparable in all compounds. $\mathrm{K}_{2} \mathrm{Mn}_{2}(\mathrm{tfa})_{6}(\mathrm{tfaH})_{2} \cdot \mathrm{H}_{2} \mathrm{O}$ is the sole exception to this trend. In this compound, a weaker $\mathrm{Mn}-\mathrm{O}(\mathrm{tfa})$ interaction appears at $-0.044 \mathrm{au}$. This interaction occurs between manganese and a carboxylic oxygen that participates as an acceptor in a hydrogen bond with a protonated trifluoroacetato ligand. The nucleophilicity of the carboxylic oxygen is thus reduced, so is the strength of the corresponding interaction with the manganese cation. Finally, we note that $\mathrm{Mn}-\mathrm{O}\left(\mathrm{H}_{2} \mathrm{O}\right)$ interactions in $\mathrm{K}_{2} \mathrm{Mn}_{2}(\mathrm{tfa})_{6}(\mathrm{tfaH})_{2} \cdot \mathrm{H}_{2} \mathrm{O}$ and $\mathrm{Rb}_{2} \mathrm{Mn}_{2}(\mathrm{tfa})_{6} \cdot \mathrm{H}_{2} \mathrm{O}$ have comparable strengths $\left(-0.048<\operatorname{sign}\left(\lambda_{2}\right) \rho\right.$ $<-0.044$ a.u.). A similar remark holds for $\mathrm{Mn}-\mathrm{O}(\mathrm{tfaH})$ interactions in $\mathrm{Na}_{2} \mathrm{Mn}_{2}(\mathrm{tfa})_{6}(\mathrm{tfaH})$ and $\mathrm{K}_{2} \mathrm{Mn}_{2}(\mathrm{tfa})_{6}(\mathrm{tfaH})_{2} \cdot \mathrm{H}_{2} \mathrm{O}(-0.041<$ $\operatorname{sign}\left(\lambda_{2}\right) \rho<-0.037$ a.u.).

Hydrogen Bonds. Hydrogen bonds appear in region B of the NCI plots shown in Figure 3; this region is absent in $\mathrm{CsMn}(\mathrm{tfa})_{3}$ since it has no hydrogen atoms. Hydrogen bonds are established with acuo (as in $\mathrm{K}_{2} \mathrm{Mn}_{2}(\mathrm{tfa})_{6}(\mathrm{tfaH})_{2} \cdot \mathrm{H}_{2} \mathrm{O}$ and $\mathrm{Rb}_{2} \mathrm{Mn}_{2}(\mathrm{tfa})_{6} \cdot \mathrm{H}_{2} \mathrm{O}$ ) and/or protonated trifluoroacetato ligands as hydrogen donors (as in $\mathrm{Na}_{2} \mathrm{Mn}_{2}(\mathrm{tfa})_{6}(\mathrm{tfaH})$ and $\left.\mathrm{K}_{2} \mathrm{Mn}_{2}(\mathrm{tfa})_{6}(\mathrm{tfaH})_{2} \cdot \mathrm{H}_{2} \mathrm{O}\right)$. Threedimensional NCI plots of hydrogen bonds in $\mathrm{Na}_{2} \mathrm{Mn}_{2}(\mathrm{tfa})_{6}(\mathrm{tfaH})$, $\mathrm{K}_{2} \mathrm{Mn}_{2}(\mathrm{tfa})_{6}(\mathrm{tfaH})_{2} \cdot \mathrm{H}_{2} \mathrm{O}$, and $\mathrm{Rb}_{2} \mathrm{Mn}_{2}(\mathrm{tfa})_{6} \cdot \mathrm{H}_{2} \mathrm{O}$ are shown in Figure 5. A well-defined disc-shaped isosurface is observed in all cases, as expected for hydrogen bonds. ${ }^{38}$ Inspection of Table 2 reveals a broad range of $\operatorname{sign}\left(\lambda_{2}\right) \rho$ values. These values depend on the hydrogen donor involved. Hydrogen bonds involving acuo donors do not vary significantly upon changing the alkali metal. By contrast, those involving protonated trifluoroacetato a) $\mathrm{Na}_{2} \mathrm{Mn}_{2}(\mathrm{tfa})_{6}(\mathrm{tfaH})$

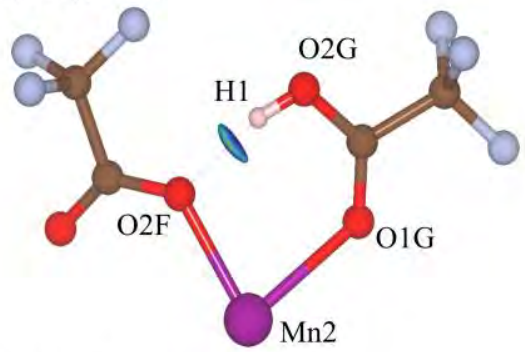

b) $\mathrm{K}_{2} \mathrm{Mn}_{2}(\mathrm{tfa})_{6}(\mathrm{tfaH})_{2} \cdot \mathrm{H}_{2} \mathrm{O}$

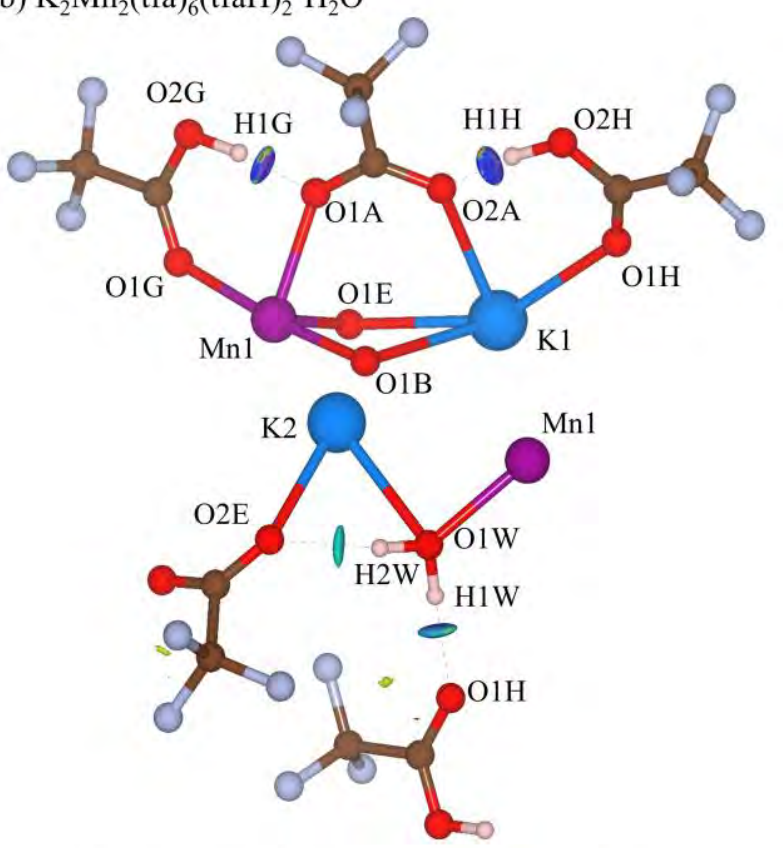

c) $\mathrm{Rb}_{2} \mathrm{Mn}_{2}(\mathrm{tfa})_{6} \cdot \mathrm{H}_{2} \mathrm{O}$

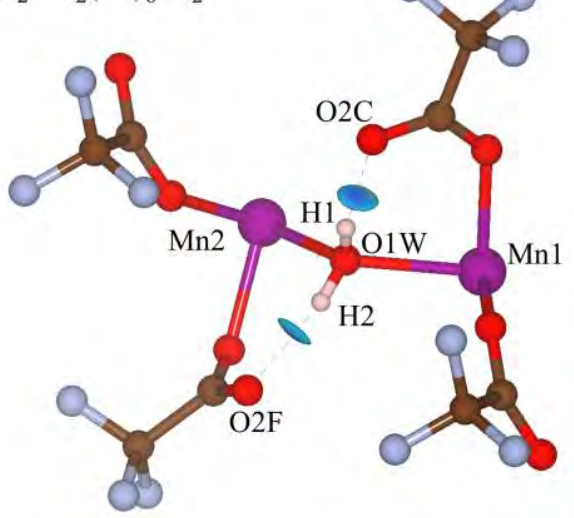

Figure 5. Three-dimensional NCI plots of hydrogen bonds in a) $\mathrm{Na}_{2} \mathrm{Mn}_{2}(\mathrm{tfa})_{6}(\mathrm{tfaH}), \quad$ b) $\quad \mathrm{K}_{2} \mathrm{Mn}_{2}(\mathrm{tfa})_{6}(\mathrm{tfaH})_{2} \cdot \mathrm{H}_{2} \mathrm{O}, \quad$ and $\left.\mathrm{c}\right)$ $\mathrm{Rb}_{2} \mathrm{Mn}_{2}(\mathrm{tfa})_{6} \cdot \mathrm{H}_{2} \mathrm{O}$. Surfaces are colored in the [-0.07, 0.07] a.u. range of $\operatorname{sign}\left(\lambda_{2}\right) \rho$ (isosurface $s=0.5$ a.u.).

donors exhibit a large variation upon going from sodium to potassium. Analysis of hydrogen bonds for each compound shows that only one bond is observed in $\mathrm{Na}_{2} \mathrm{Mn}_{2}(\mathrm{tfa})_{6}(\mathrm{tfaH})$ and involves a protonated trifluoroacetato ligand. This bond is characterized by $\operatorname{sign}\left(\lambda_{2}\right) \rho=-0.042$ a.u., a value between that of $\mathrm{Mn}-\mathrm{O}(\mathrm{tfa})$ and $\mathrm{Mn}-\mathrm{O}(\mathrm{tfaH})$ interactions. Four bonds are observed in $\mathrm{K}_{2} \mathrm{Mn}_{2}(\mathrm{tfa})_{6}(\mathrm{tfaH})_{2} \cdot \mathrm{H}_{2} \mathrm{O}$ : two involve acuo ligands $(-0.036<$ $\operatorname{sign}\left(\lambda_{2}\right) \rho<-0.023$ a.u), while the other two involve protonated trifluoroacetato ligands $\left(-0.072<\operatorname{sign}\left(\lambda_{2}\right) \rho<-0.078\right.$ a.u). Com- 
a) $\mathrm{K} 1, \mathrm{~K}_{2} \mathrm{Mn}_{2}(\mathrm{tfa})_{6}(\mathrm{tfaH})_{2} \cdot \mathrm{H}_{2} \mathrm{O}$

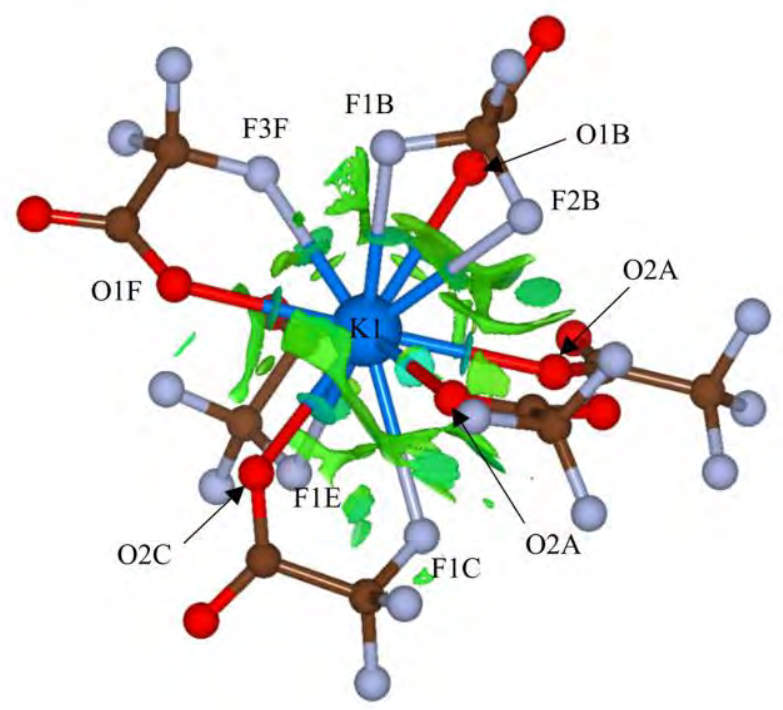

b) $\mathrm{K} 2, \mathrm{~K}_{2} \mathrm{Mn}_{2}(\mathrm{tfa})_{6}(\mathrm{tfaH})_{2} \cdot \mathrm{H}_{2} \mathrm{O}$

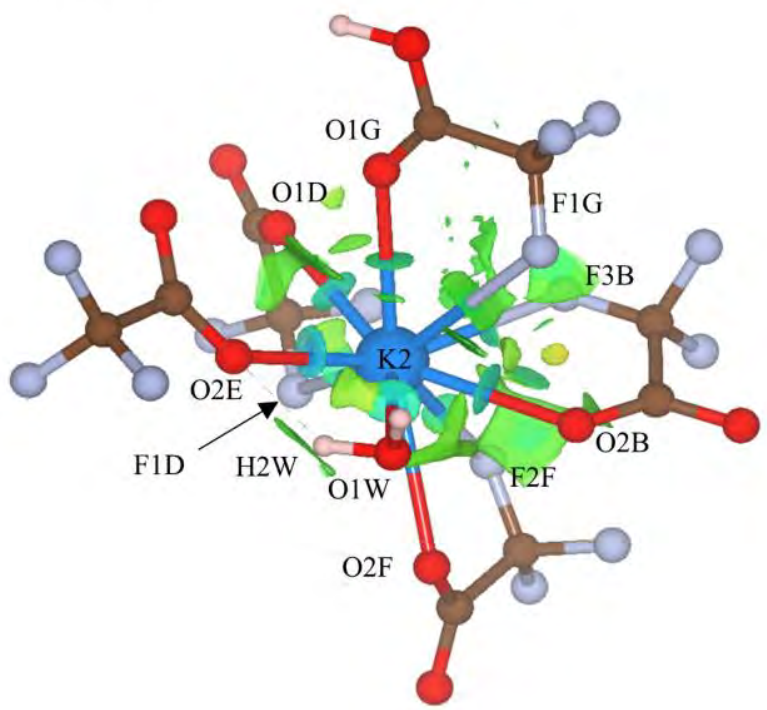

Figure 6. Three-dimensional NCI plots of potassium-oxygen and potassium-fluorine interactions in $\mathrm{K}_{2} \mathrm{Mn}_{2}(\mathrm{tfa})_{6}(\mathrm{tfaH})_{2} \cdot \mathrm{H}_{2} \mathrm{O}$. Plots are shown for the two distinct potassium atoms in the structure. Surfaces are colored in the $[-0.04,0.04]$ a.u. range of $\operatorname{sign}\left(\lambda_{2}\right) \rho$ (isosurface $s$ $=0.5$ a.u.). Electrostatic $\mathrm{K}-\mathrm{O} / \mathrm{F}$ interactions are characterized by disc-shaped isosurfaces. van der Waals interactions, on the other hand, are depicted by diffuse isosurfaces.

parison of the absolute values of the electron density for hydrogen bonds and manganese-oxygen bonds involving a protonated trifluoroacetato ligand shows the former are stronger in this crystal. Noteworthy, hydrogen bonds in this compound appear to have a strength comparable to that of interactions established between manganese and oxygen donors from a negatively charged trifluoroacetato ligand. Finally, two hydrogen bonds occur in $\mathrm{Rb}_{2} \mathrm{Mn}_{2}(\mathrm{tfa})_{6} \cdot \mathrm{H}_{2} \mathrm{O}$. Both involve the same acuo ligand and display $\operatorname{sign}\left(\lambda_{2}\right) \rho$ values similar to those observed in $\mathrm{K}_{2} \mathrm{Mn}_{2}(\mathrm{tfa})_{6}(\mathrm{tfaH})_{2} \cdot \mathrm{H}_{2} \mathrm{O}$. The range of $\operatorname{sign}\left(\lambda_{2}\right) \rho$ values, however, is significantly narrower. This behavior is attributed to the fact that the acuo ligand in $\mathrm{Rb}_{2} \mathrm{Mn}_{2}(\mathrm{tfa})_{6} \cdot \mathrm{H}_{2} \mathrm{O}$ establishes two hydrogen bonds with two trifluoroacetato ligands (Figure 5c), whereas in $\mathrm{K}_{2} \mathrm{Mn}_{2}(\mathrm{tfa})_{6}(\mathrm{tfaH})_{2} \cdot \mathrm{H}_{2} \mathrm{O}$ it establishes bonds with both, a trifluoroacetato and a protonated trifluoroacetato ligand (Figure $5 \mathbf{b})$.

Alkali-Oxygen Interactions. Alkali-oxygen interactions appear in region $\mathrm{C}$ of the NCI plots shown in Figure 3. With the exception of $\mathrm{K}_{2} \mathrm{Mn}_{2}(\mathrm{tfa})_{6}(\mathrm{tfaH})_{2} \cdot \mathrm{H}_{2} \mathrm{O}$, alkali-oxygen interactions are established with carboxylic oxygens belonging to trifluoroacetato and/or protonated trifluoroacetato ligands. Electron density values for the fingerprints of these interactions are typical of weak electrostatic interactions. ${ }^{37}$ This character is clearly seen in the threedimensional NCI plots shown in Figure 6 for the case of $\mathrm{K}_{2} \mathrm{Mn}_{2}(\mathrm{tfa})_{6}(\mathrm{tfaH})_{2} \cdot \mathrm{H}_{2} \mathrm{O}$; plots for the sodium, rubidium, and cesium compounds are given in the Supporting Information (see Figure S2). Density gradient isosurfaces with well-defined disclike shapes are observed in the internuclear axis between alkali and oxygen atoms. These surfaces are indicative of a highly localized interaction. Inspection of Table 2 shows that average $\operatorname{sign}\left(\lambda_{2}\right) \rho$ values for alkali-oxygen interactions decrease upon going from sodium to cesium, and that the amplitude of the range of values remains roughly constant through the series. The relative strength of these interactions is in agreement with their electrostatic nature. As the alkali cation becomes larger, more electropositive, and less polarizing it establishes increasingly weaker and more diffuse electrostatic interactions with trifluoroacetato and protonated trifluoroacetato ligands. As observed earlier for other noncovalent interactions, potassium-oxygen interactions deviate from this trend. These interactions display the lowest average $\operatorname{sign}\left(\lambda_{2}\right) \rho$ value and the broadest range of values of the entire series. Inspection of Figure $\mathbf{6 b}$ sheds light on the origin of the distinct behavior of potassium-oxygen interactions in this compound. The abnormally low $\operatorname{sign}\left(\lambda_{2}\right) \rho$ value may be attributed to a weak interaction between one of the two nonequivalent potassium cations and an acuo ligand (K2-O1W). The oxygen belonging to the acuo ligand is involved in two hydrogen bonds and, as a result, its nucleophilicity is weakened and so is the corresponding potassium-oxygen interaction.

Alkali-Fluorine Interactions. Alkali-organofluorine interactions are located in region D of the NCI plots shown in Figure 3. Special emphasis was placed on getting in-depth understanding of these interactions. Three tools were combined to distinguish between electrostatic and van der Waals interactions: (i) $\operatorname{sign}\left(\lambda_{2}\right) \rho$ values, (ii) the NCI reduced density gradient profile, ${ }^{67}$ and (iii) BCPs along the internuclear axis. BCPs are expected in localized interactions but not necessarily in weak delocalized ones. ${ }^{29}$ In our case, the absence of BCPs may indicate weak van der Waals interactions. Inspection of Table 2 shows that the average value of $\operatorname{sign}\left(\lambda_{2}\right) \rho$ for electrostatic interactions decreases upon going from sodium to cesium. Accordingly, cesium-fluorine interactions in $\mathrm{CsMn}(\mathrm{tfa})_{3}$ are more diffuse than in $\mathrm{Na}_{2} \mathrm{Mn}_{2}(\mathrm{tfa})_{6}(\mathrm{tfaH})$ (see Figures S2a-e). Analysis of alkalifluorine electrostatic interactions in $\mathrm{Na}_{2} \mathrm{Mn}_{2}(\mathrm{tfa})_{6}(\mathrm{tfaH})$ reveals $\operatorname{sign}\left(\lambda_{2}\right) \rho$ values ranging from -0.011 to -0.006 a.u. These are characterized by disc-shaped isosurfaces (see Figures S2a and S2b). BCPs were found for interactions Na1-F1A/F3E and Na2F1C/F2D. By contrast, Na1-F1B/FG van der Waals interactions exhibit $\operatorname{sign}\left(\lambda_{2}\right) \rho$ values that lie in the -0.004 to -0.002 a.u. range and, as expected, their corresponding NCI profiles show diffuse surfaces; ${ }^{37}$ no BCPs were found for these interactions. In the case of $\mathrm{K}_{2} \mathrm{Mn}_{2}(\mathrm{tfa})_{6}(\mathrm{tfaH})_{2} \cdot \mathrm{H}_{2} \mathrm{O}$, seven electrostatic interactions are observed; these are $\mathrm{K} 1-\mathrm{F} 1 \mathrm{~B} / \mathrm{F} 1 \mathrm{C} / \mathrm{F} 1 \mathrm{E} / \mathrm{F} 3 \mathrm{~F}$ and $\mathrm{K} 2-$ F1D/F2F/F3B. The distinct crystal-chemistry of this hybrid is confirmed once again upon inspection of Table 2, as some of these $\mathrm{K}-\mathrm{F}$ interactions exhibit higher electron densities than $\mathrm{K}-\mathrm{O}$ 
interactions. Dispersive interactions in this compound involve $\mathrm{K} 1-\mathrm{F} 2 \mathrm{~B}$ and $\mathrm{K} 2-\mathrm{F} 1 \mathrm{G}$ and, as expected, their corresponding NCI surfaces are diffuse (see Figures $\mathbf{6 a}$ and $\mathbf{6 b}$ ). Similar to the case of sodium, BCPs were found for electrostatic interactions but not for van der Waals interactions. Analysis of the three-dimensional NCI profiles (see Figures S2c and S2d) and BCPs in $\mathrm{Rb}_{2} \mathrm{Mn}_{2}(\mathrm{tfa})_{6} \cdot \mathrm{H}_{2} \mathrm{O}$ demonstrates that $\mathrm{Rb} 1-$ $\mathrm{F} 1 \mathrm{~A} / \mathrm{F} 3 \mathrm{~A} / \mathrm{F} 1 \mathrm{D} / \mathrm{F} 3 \mathrm{~F} / \mathrm{F} 1 \mathrm{C}$ and Rb2-F1B/F2B/F3C/F2D interactions are directional (electrostatic), while Rb1-F1E/F2E/F3E/F2A and $\mathrm{Rb} 2-\mathrm{F} 3 \mathrm{D} / \mathrm{F} 3 \mathrm{E} / \mathrm{F} 1 \mathrm{~F}$ are delocalized (van der Waals). Finally, all alkali-fluorine interactions in $\mathrm{CsMn}(\mathrm{tfa})_{3}$ appear to be electrostatic, as shown by well-defined disc-shaped isosurfaces (see Figure S2e). Additionally, all of them present BCPs.

In the case of electrostatic alkali-fluorine interactions, a simple charge model was used to identify them and rank their relative strength. In this model, we considered interactions between point charges separated by the equilibrium distance and interacting through a Coulomb-type potential. Charges were computed via Bader analysis. ${ }^{68}$ The strengths of electrostatic interactions were linearly normalized to facilitate comparison between bimetallic trifluoroacetates. This was accomplished by using the strongest interaction within each compound as a reference value and calcu-

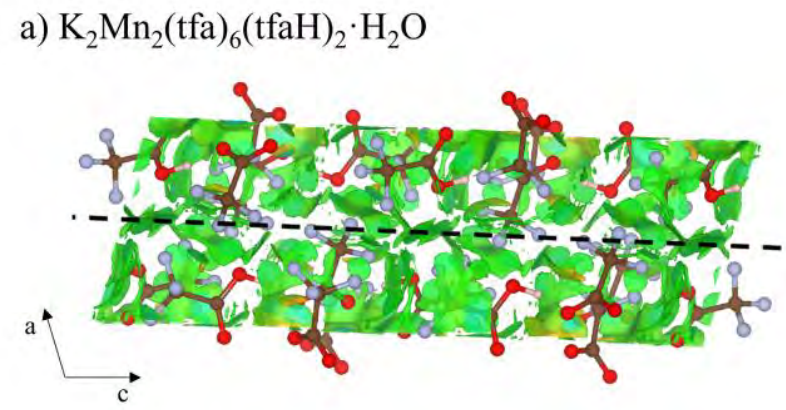

b) $\operatorname{CsMn}(\mathrm{tfa})_{3}$

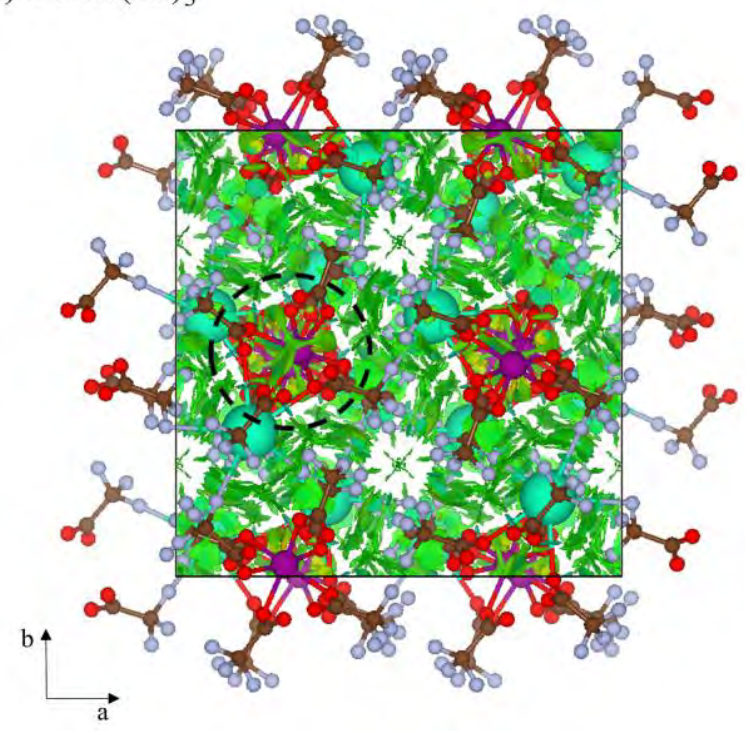

Figure 7. Three-dimensional NCI plots of dispersive interactions in a) $\mathrm{K}_{2} \mathrm{Mn}_{2}(\mathrm{tfa})_{6}(\mathrm{tfaH})_{2} \cdot \mathrm{H}_{2} \mathrm{O}$ and b) $\mathrm{CsMn}(\mathrm{tfa})_{3}$. Surfaces are colored in the $[-0.06,0.06]$ a.u. range of $\operatorname{sign}\left(\lambda_{2}\right) \rho$ (isosurface $s=$ 0.5 a.u.). As expected for dispersive interactions, isosurfaces appear extended and diffuse. The interlayer space in $\mathrm{K}_{2} \mathrm{Mn}_{2}(\mathrm{tfa})_{6}(\mathrm{tfaH})_{2} \cdot \mathrm{H}_{2} \mathrm{O}$ and the threads in $\mathrm{CsMn}(\mathrm{tfa})_{3}$ are indicated with dashed lines. Cesium atoms are shown in turquoise green, manganese in purple, oxygen in red, carbon in brown, and fluorine in grey. lating a strength coefficient that takes a maximum value of 1.0; additional details are provided in the Supporting Information (see Table S3). Analysis of the electrostatic contributions within this model further supports the distinction between electrostatic and van der Waals interactions. Interactions classified as electrostatic show relative strength coefficients between 0.95 and $1.0(\mathrm{Na})$, 0.88 and $1.0(\mathrm{~K}), 0.92$ and $1.0(\mathrm{Rb})$, and 0.91 and $1.0(\mathrm{Cs})$. In contrast, values for van der Waals interactions are significantly lower and range from 0.84 to $0.86(\mathrm{Na}), 0.80(\mathrm{~K})$, and 0.83 to 0.85 $(\mathrm{Rb})$.

\section{Analysis of van der Waals Interactions}

van der Waals interactions were quantified using the dispersive term in the total crystal energy, which was calculated using Grimme's D2 scheme. ${ }^{47}$ Dispersive interactions contribute ca. 2 $\%$ of the total crystal energy in $\mathrm{Na}_{2} \mathrm{Mn}_{2}(\mathrm{tfa})_{6}(\mathrm{tfaH})$, $\mathrm{K}_{2} \mathrm{Mn}_{2}(\mathrm{tfa})_{6}(\mathrm{tfaH})_{2} \cdot \mathrm{H}_{2} \mathrm{O}$, and $\mathrm{Rb}_{2} \mathrm{Mn}_{2}(\mathrm{tfa})_{6} \cdot \mathrm{H}_{2} \mathrm{O}$; this contribution doubles for CsMn(tfa) ${ }_{3}$ (ca. $4 \%$ ) (see Table S4). The significance of van der Waals interactions for crystal cohesion and packing was further analyzed in the cases of $\mathrm{K}_{2} \mathrm{Mn}_{2}(\mathrm{tfa})_{6}(\mathrm{tfaH})_{2} \cdot \mathrm{H}_{2} \mathrm{O}$ and $\mathrm{CsMn}(\mathrm{tfa})_{3}$. These crystals have well-defined building blocks: double layers stacked along the $a$ axis and held together by van der Waals forces $\left(\mathrm{K}_{2} \mathrm{Mn}_{2}(\mathrm{tfa})_{6}(\mathrm{tfaH})_{2} \cdot \mathrm{H}_{2} \mathrm{O}\right)$, and a combination of layers stacked along the $b$ axis and threads parallel to the $c$ axis $\left(\mathrm{CsMn}(\mathrm{tfa})_{3}\right)$. Computation of the cohesive energy between these building blocks yields $0.17 \mathrm{eV} / \mathrm{Mn}$ atom (layers in $\left.\mathrm{K}_{2} \mathrm{Mn}_{2}(\mathrm{tfa})_{6}(\mathrm{tfaH})_{2} \cdot \mathrm{H}_{2} \mathrm{O}\right), \quad 1.23 \mathrm{eV} / \mathrm{Mn}$ atom (layers in $\left.\mathrm{CsMn}(\mathrm{tfa})_{3}\right)$, and $2.38 \mathrm{eV} / \mathrm{Mn}$ atom (threads in $\left.\mathrm{CsMn}(\mathrm{tfa})_{3}\right)$. These results further confirm that van der Waals interactions are more significant in CsMn $(\mathrm{tfa})_{3}$ than in $\mathrm{K}_{2} \mathrm{Mn}_{2}(\mathrm{tfa})_{6}(\mathrm{tfaH})_{2} \cdot \mathrm{H}_{2} \mathrm{O}$. Unit cells employed in these calculations are given in the Supporting Information (Figure S3).

van der Waals interactions in $\mathrm{K}_{2} \mathrm{Mn}_{2}(\mathrm{tfa})_{6}(\mathrm{tfaH})_{2} \cdot \mathrm{H}_{2} \mathrm{O}$ and $\mathrm{CsMn}(\mathrm{tfa})_{3}$ were further probed by means of three-dimensional NCI plots; these are shown in Figures $7 \mathbf{a}$ and $\mathbf{7 b}$. The profile of these interactions in $\mathrm{K}_{2} \mathrm{Mn}_{2}(\mathrm{tfa})_{6}(\mathrm{tfaH})_{2} \cdot \mathrm{H}_{2} \mathrm{O}$ displays extended green isosurfaces, as expected for dispersive interactions. Fluorine-fluorine and fluorine-oxygen interactions between atoms belonging to different trifluoroacetato ligands are observed (Figure 7a). In the case of $\mathrm{CsMn}(\mathrm{tfa})_{3}$, van der Waals interactions between threads are depicted by a large number of green isosurfaces (Figure 7b). An interesting finding is that alkali-fluorine interactions in $\mathrm{CsMn}(\mathrm{tfa})_{3}$ are of electrostatic rather than dispersive nature, despite the large number of green isosurfaces and the large contribution of dispersive interactions to crystal cohesion. This contribution can be appreciated by noting that dispersive interactions are present in the interlayer space in $\mathrm{K}_{2} \mathrm{Mn}_{2}(\mathrm{tfa})_{6}(\mathrm{tfaH})_{2} \cdot \mathrm{H}_{2} \mathrm{O}$ (Figure 7a) and over the entire structure in $\mathrm{CsMn}(\mathrm{tfa})_{3}$ (Figure 7b). Even though $\mathrm{K}_{2} \mathrm{Mn}_{2}(\mathrm{tfa})_{6}(\mathrm{tfaH})_{2} \cdot \mathrm{H}_{2} \mathrm{O}$ consists of layers that are held together by dispersive interactions between trifluoroacetato ligands, the dispersive contribution to the total energy is the same as for $\mathrm{Na}_{2} \mathrm{Mn}_{2}(\mathrm{tfa})_{6}(\mathrm{tfaH})$ and $\mathrm{Rb}_{2} \mathrm{Mn}_{2}(\mathrm{tfa})_{6} \cdot \mathrm{H}_{2} \mathrm{O}$, which exhibit a tridimensional mesh of electrostatic interactions between metals and trifluoroacetato ligands. This result, along with the unusually strong hydrogen bonds present in $\mathrm{K}_{2} \mathrm{Mn}_{2}(\mathrm{tfa})_{6}(\mathrm{tfaH})_{2} \cdot \mathrm{H}_{2} \mathrm{O}$, indicate that this crystal adopts a layered structure in order to maximize the number of hydrogen bonds between protonoated trifluoroacetato ligands

Major Crystal-Chemical Trends

The main crystal-chemical trends observed across the series of alkali-manganese(II) bimetallic fluoroacetates are summarized in the following bullet points.

- Manganese-oxygen was the strongest noncovalent interaction occurring in the series of crystals under study. This interaction was of electrostatic nature. Its strength was independent of the 
alkali metal present in the structure but strongly dependent on the oxygen donor $\left(\mathrm{Mn}-\mathrm{O}(\mathrm{tfa})>\mathrm{Mn}-\mathrm{O}\left(\mathrm{H}_{2} \mathrm{O}\right)>\mathrm{Mn}-\mathrm{O}(\mathrm{tfaH})\right)$.

- The strength of hydrogen bonds involving acuo donors did not vary significantly upon changing the alkali metal. Conversely, those involving protonated trifluoroacetato donors exhibited a pronounced dependence on the alkali metal, being stronger for $\mathrm{K}_{2} \mathrm{Mn}_{2}(\mathrm{tfa})_{6}(\mathrm{tfaH})_{2} \cdot \mathrm{H}_{2} \mathrm{O}$.

- Alkali-oxygen interactions could be described as weak electrostatic interactions and, as expected, their strength decreased upon going from sodium to cesium.

- Alkali-fluorine interactions were of electrostatic or van der Waals type. Both types of interactions were observed in sodium-, potassium-, and rubidium-manganese crystals. Only electrostatic interactions were present in $\mathrm{CsMn}(\mathrm{tfa})_{3}$.

- The dispersive contribution to the total crystal energy was almost the same for $\mathrm{K}_{2} \mathrm{Mn}_{2}(\mathrm{tfa})_{6}(\mathrm{tfaH})_{2} \cdot \mathrm{H}_{2} \mathrm{O}, \mathrm{Na}_{2} \mathrm{Mn}_{2}(\mathrm{tfa})_{6}(\mathrm{tfaH})$, and $\mathrm{Rb}_{2} \mathrm{Mn}_{2}(\mathrm{tfa})_{6} \cdot \mathrm{H}_{2} \mathrm{O}$.

- The relative strengths of noncovalent interactions in the twodimensional, layered $\mathrm{K}_{2} \mathrm{Mn}_{2}(\mathrm{tfa})_{6}(\mathrm{tfaH})_{2} \cdot \mathrm{H}_{2} \mathrm{O}$ crystal deviated sharply from those observed in the other members of the series. Hydrogen bonds established by protonated trifluoroacetato ligands located in the interlayer space appeared to be as strong as manganese-oxygen electrostatic interactions. Likewise, interactions between potassium and fluorine exhibited higher electron densities than those between potassium and oxygen. The distinct two-dimensional crystal structure of $\mathrm{K}_{2} \mathrm{Mn}_{2}(\mathrm{tfa})_{6}(\mathrm{tfaH})_{2} \cdot \mathrm{H}_{2} \mathrm{O}$ is therefore attributed to this unique balance of noncovalent interactions. By adopting this spatial arrangement, the number of strong hydrogen bonds was maximized. This result illustrates the significance of quantitatively probing noncovalent interactions, as these may provide a rational pathway to design anisotropic hybrid functional crystals.

\section{CONCLUSIONS}

Noncovalent interactions in alkali-manganese(II) bimetallic fluorinated crystals were quantitatively mapped and ranked using the NCI approach. Their strength, spatial localization, and compositional dependence were established. Quantitative chemical principles were outlined to gain insight into the compositional dependence of noncovalent metal-ligand interactions in hybrid fluorinated crystals. These principles should contribute to the design and predictive synthesis of hybrid crystals with tailored dimensionality and crystal packing via compositional tuning of noncovalent interactions. From a methodological standpoint, the combination of NCI methodology, BCPs search, a simple charge model, and calculation of the dispersive contribution to the total energy served to identify and quantitatively characterize alkali-organofluorine interactions, which are challenging to probe by other methods. The NCI approach allowed us to go beyond the "sum of radii" approximation routinely used to empirically define metal-organohalogen contacts, and enabled identification of these contacts based on rigorous quantum-chemical principles. A similar analysis would not have been possible solely on the basis of the total energy or the wavefunction.

\section{ASSOCIATED CONTENT}

\section{Supporting Information}

Supporting Information is available free of charge at the ACS Publications website, http://pubs.acs.org. The following Supporting Information is provided: (1) Details of DFT methodology selection. (2) Additional three-dimensional NCI plots of manganese-oxygen and alkali-oxygen/fluorine interactions. (3) Details of the charge model employed for classifying noncovalent alkalifluorine interactions. (4) Calculation of the dispersion contribu- tion to the total crystal energy of $\mathrm{Na}_{2} \mathrm{Mn}_{2}(\mathrm{tfa})_{6}(\mathrm{tfaH})$, $\mathrm{K}_{2} \mathrm{Mn}_{2}(\mathrm{tfa})_{6}(\mathrm{tfaH})_{2} \cdot \mathrm{H}_{2} \mathrm{O}, \mathrm{Rb}_{2} \mathrm{Mn}_{2}(\mathrm{tfa})_{6} \cdot \mathrm{H}_{2} \mathrm{O}$, and $\mathrm{CsMn}(\mathrm{tfa})_{3}$. (5) Unit cells employed in the calculation of the interaction energies between layers and threads in $\mathrm{K}_{2} \mathrm{Mn}_{2}(\mathrm{tfa})_{6}(\mathrm{tfaH})_{2} \cdot \mathrm{H}_{2} \mathrm{O}$ and $\operatorname{CsMn}(\mathrm{tfa})_{3}$.

\section{AUTHOR INFORMATION}

\section{Corresponding Authors}

*julen@unizar.es; contrera@lct.jussieu.fr

\section{Notes}

The authors declare no competing financial interests.

\section{ACKNOWLEDGMENT}

J.M. acknowledges the financial support provided by the Spanish MECD (FPU14/06003 and EST16/00466). In addition, the resources from the supercomputer "memento", technical expertise and assistance provided by BIFI-ZCAM (Universidad de Zaragoza) are acknowledged. F.A.R. would like to acknowledge the financial support of the Department of Chemistry at Wayne State University. J.C.-G. acknowledges CALSIMLAB and the ANR within the Investissements d'Avenir program under reference ANR-11-IDEX-0004-02.

\section{REFERENCES}

(1) Kleigrewe, N.; Brackemeyer, Th.; Kehr, G.; Fröhlich, R; Erker, G. Synthesis and Structural Behavior of the Tris $(\eta-$ cyclopentadienyl)zirconium-Betaine Complex $\mathrm{Cp}_{2}\left[\eta^{5}-\mathrm{C}_{5} \mathrm{H}_{4} \mathrm{~B}\left(\mathrm{C}_{6} \mathrm{~F}_{5}\right)_{3}\right] \mathrm{Zr}$. Organometallics 2001, 20, 1952-1955.

(2) Erker, G. The (butadiene)metal Complex/B(C6F5)3 Pathway to Homogeneous Single Component Ziegler-Natta Catalyst Systems. Chem. Commun. 2003, 0, 1469-1476.

(3) Sarazin, Y.; Liu, B.; Roisnel, T.; Maron, L.; Carpentier, J.-F. Discrete, Solvent-free Alkaline-earth Metal Cations: Metal ‥Fluorine Interactions and ROP Catalytic Activity. J. Am. Chem. Soc. 2011, 133, 9069 9087.

(4) Samuels, J. A.; Chiang, W.-C.; Yu, C.-P.; Apen, E.; Smith, D. C.; Baxter, D. V.; Caulton, K. G., Chemical Vapor Deposition of Metal Fluorides Using Sodium and Zirconium Fluoroalkoxides. Chem. Mater. 1994, 6, 1684-1692.

(5) Troyanov, S. I.; Gorbenko, O. Y.; Bosak, A. A., Synthesis, Crystal Structure and Properties of Manganese(II) Hexafluoroacetylacetonates $\mathrm{Mn}(\mathrm{hfa})_{2}\left(\mathrm{H}_{2} \mathrm{O}\right)_{2}$ and $\mathrm{KMn}(\mathrm{hfa})_{3}$. Polyhedron 1999, 18, 3505-3509.

(6) Tahir, A. A.; Mazhar, M.; Hamid, M.; Zeller, M.; Hunter, A. D., Heterobimetallic Copper-Barium Complexes for Deposition of Composite Oxide Thin Films. N. J. Chem. 2009, 33, 1535-1541.

(7) Mansoor, M. A.; Ismail, A.; Yahya, R.; Arifin, Z.; Tiekink, E. R. T.; Weng, N. S.; Mazhar, M.; Esmaeili, A. R., Perovskite-Structured $\mathrm{PbTiO}_{3}$ Thin Films Grown from a Single-Source Precursor. Inorg. Chem. 2013, $52,5624-5626$.

(8) O'Hagan, D. Fluorine in Health Care: Organofluorine Containing Blockbuster Drugs. J. Fluor. Chem. 2010, 131, 1071-1081.

(9) Paulini, R; Müller, K.; Diederich, F. Orthogonal Multipolar Interactions in Structural Chemistry and Biology. Angew. Chem. Int. Ed. 2005, 44, 1788-1805.

(10) Pollock, J.; Dmitry, B.; Lund, G.; Purohit, T.; DygudaKazimierowicz, E.; Grembecka, J.; Cierpicki, T. Rational Design of Orthogonal Multipolar Interactions with Fluorine in Protein-Ligand Complexes. J. Med. Chem. 2015, 58, 7465-7474.

(11) Mishra, S.; Daniele, S.; Ledoux, G.; Jeanneau, E.; Joubert, M.-F., Heterometallic Na-Y(Ln) Trifluoroacetate Diglyme Complexes as Novel Single-Source Precursors for Upconverting $\mathrm{NaYF}_{4}$ Nanocrystals CoDoped with $\mathrm{Yb}$ and Er/Tm Ions. Chem. Commun. 2010, 46, 3756-3758.

(12) Mishra, S.; Ledoux, G.; Jeanneau, E.; Daniele, S.; Joubert, M. F., Novel Heterometal-Organic Complexes as First Single Source Precursors for Upconverting $\mathrm{NaY}_{(\mathrm{Ln}) \mathrm{F}_{4}}(\mathrm{Ln}=\mathrm{Yb}, \mathrm{Er}, \mathrm{Tm})$ Nanomaterials. Dalton Trans. 2012, 41, 1490-1502. 
(13) Chen, Y.; Mishra, S.; Ledoux, G.; Jeanneau, E.; Daniel, M.; Zhang, J.; Daniele, S., Direct Synthesis of Hexagonal $\mathrm{NaGdF}_{4}$ Nanocrystals from a Single-Source Precursor: Upconverting $\mathrm{NaGdF}_{4}: \mathrm{Yb}^{3+}, \mathrm{Tm}^{3+}$ and Its Composites with $\mathrm{TiO}_{2}$ for Near-IR-Driven Photocatalysis. Chem. Asian J. 2014, 9, 2415-2421.

(14) Dhanapala, B. D.; Munasinghe, H. N.; Suescun, L.; Rabuffetti, F. A. Bimetallic Trifluoroacetates as Single-Source Precursors for AlkaliManganese Fluoroperovskites. Inorg. Chem. 2017, 56, 13311-13320.

(15) Pfletscher, M.; Hölscher, S.; Wöler, C.; Mezger, M.; Giese, M. Structure-Property relationships in Hydrogen-Bonded Liquid Crystals. Chem. Mater. 2017, 29, 8462-8471.

(16) Yandanova, E. S.; Ivanov, D. M.; Kuznetsov, M. L.; Starikov, A. G.; Starovam G. L.; Kukushin, V. Y. Recognition of S $\cdots \mathrm{Cl}$ Chalcogen Bonding in Metal-Bound Alkylthiocyanates. Cryst. Growth Des. 2016, 16 2979-2987.

(17) Plenio, H., The Coordination Chemistry of the CF Unit in Fluorocarbons. Chem. Rev. 1997, 97, 3363-3384.

(18) Plenio, H. The Coordination Chemistry of Fluorine in Fluorocarbons. ChemBioChem 2004, 5, 650-655.

(19) Zhou, P.; Zou, J.; Tian, F.; Shang, Z. Fluorine Bonding - How Does it Work in Protein-Ligand Interactions? J. Chem. Inf. Model. 2009, 49, 2344-2355.

(20) Buchanan, W.D. and Ruhlandt-Senge, K. M-F Interactions and Heterobimetallics: Furthering the Understanding of Heterobimetallic Stabilization. Chem. Eur. J. 2013, 19, 10708-10715.

(21) Lee A. Y.; Park, D. Y.; Jeong, M. S. Correlational study of halogen tuning effect in hybrid perovskite single crystals with Raman scattering, X-ray diffraction, and absorption. J. Alloys Compd. 2018, 738, 239245.

(22) Kolesa-Dobravc, T.; Meden, A.; Perdih, F. Influence of noncovalent interactions on structures of metal - organic hybrids based on a $\left[\mathrm{VO}_{2}(2,5-\mathrm{pydc})\right]^{-}$tecton with cations of imidazole, pyridine and its derivatives. New J. Chem. 2015, 39, 4265-4277.

(23) Buchanan, W. D.; Ruhlandt-Senge, K. M-F Interactions and Heterobimetallics: Furthering the Understanding of Heterobimetallic Stabilization. Chem. Eur. J. 2013, 19, 10708-10715.

(24) Martins, M. A. P.; Rodrigues, L. V.; Meyer, A. R.; Frizzo, C. P.; Hörner, M.; Zanatta, N.; Bonacorso, H. G.; Berná, J.; Alajarín, M. Density Functional Theory and Quantum Theory of Atoms in Molecules Analysis: Influence of Intermolecular Interactions on Pirouetting Movement in Tetraalkylsuccunamide[2]rotaxanes. Cryst. Growth Des. 2017, 17, 58455857.

(25) Lu, Y.; Zhang, S.; Peng, C.; Liu, H. Interplay between Halogen and Hydrogen Bonds in 2D Self-Assembly on the Gold Surface: A FirstPrinciples Investigation. J. Phys. Chem. C 2017, 121, 24707-24720.

(26) Liu, W. -G.; Truhlar, D. G. Computational Linker Design of Highly Crystalline Metal-Organic Framework NU-1000. Chem. Mater. 2017, 29, 8073-8081.

(27) Harrison, J. A.; Arif Sajjad, A.; Schwerdtfeger, P.; Nielson, A. J. Multiple Wear C-H Intramolecular Hydrogen Bonding as an Aid to Minimizing Bond Rotation Flexibility. Cryst. Growth Des. 2016, 16, 4934 4942.

(28) Johnson, E. R.; Keinan, S.; Mori-Sanchez, P.; Contreras-Garcia, J.; Cohen, A. J.; Yang, W. T. Revealing Noncovalent Interactions. J. Am. Chem. Soc. 2010, 132, 6498-6506.

(29) Contreras-García, J.; Johnson, E. R.; Keinan, S.; Chaudret, R.; Piquemal, J. -P.; Beratan, D. N.; Yanga, W. NCIPLOT: A Program for Plotting Noncovalent Interaction Regions. J. Chem. Theory Comput. 2011, 7, 625-632.

(30) Lane, J. R.; Contreras-García, J.; Piquemal, J. -P.; Miller, B. J.; Kjaergaard, H. G. Are Bond Critical Points Really Critical for Hydrogen Bonding? J. Chem. Theory Comput. 2013, 9, 3263 - 3266.

(31) Macetti, G.; Loconte, L.; Rizzato, S.; Lo Presti, L. Intermolecular Recognition of the Antimalarial Drug Chloroquine: A Quantum Theory of Atoms in Molecules-Density Functional Theory Investigation of the Hydrated Dihydrogen Phosphate Salt from the 103 K X-ray Structure. Cryst. Growth Des. 2016, 16, 6043-6054.

(32) Kozuch, S.; Martin, J. M. L. Halogen Bonds: Benchmarks and Theoretical Analysis. J. Chem. Theory Comput. 2013, 9, 1918-1931.

(33) Gonzalez, L.; Tejedor, R. M.; Royo, E.; Gaspar, B.; Munarriz, J.; Chanthapally, A.; Serrano, J. L.; Vittal, J. J.; Uriel, S. Two-Dimensional Arrangements of Bis(haloethynyl)benzenes Combining Halogen and Hydrogen Interactions. Cryst. Growth Des. 2017, 17, 6212-6223.
(34) Otero-de-la-Roza, A.; Johnson, E. R.; Contreras-Garcia, J.; Revealing Noncovalent Interactions in Solids: NCI Plots Revised. Phys. Chem. Chem. Phys. 2012, 14, 12165-12172.

(35) Otero-de-la-Roza, A.; Luaña, V.; Tiekink, E. R. T.; ZukermanSchpector, J.; Unraveling Interactions in Molecular Crystals Using Dispersion Corrected Density Functional Theory: The Case of the Epoxydihydroarsanthrene Molecules. J. Chem. Theory Comput. 2014, 10, 50105019.

(36) Badri, Z.; Bouzková, K.; Foroutan-Nejad, C.; Marek, R. Origin of the Thermodynamic Stability of the Polymorph IV of Crystalline Barbituric Acid: Evidence from Solid-State NMR and Electron Density Analyses. Cryst. Growth Des. 2014, 14, 2763-2772.

(37) Nourmahnad, A.; Smith, M. D.; Zeller, M.; Ferrence, G. M.; Schrier, J.; Norquist, A. J. Role of Nonvcovalent Interactins in Vanadium Tellurite Chain Connectivities. Inorg. Chem. 2015, 54, 694-703.

(38) Riffet, V.; Contreras-Gracía, J.; Carrasco, J.; Calatayud, M. Alkali Ion Incorporation into $\mathrm{V}_{2} \mathrm{O}_{5}$ : a Noncovalent Interactions Analysis. J. Phys Chem. C 2016, 120, 4259-4265.

(39) Lee, J. -H.; Bristowe, N. C.; Bristowe, P. D.; Cheetham, A. K. Role of Hydrogen-Bonding and its Interplay with Octahedral Tilting in $\mathrm{CH}_{3} \mathrm{NH}_{3} \mathrm{PbI}_{3}$. Chem. Commun. 2015, 51, 6434-6437.

(40) Navas, J.; Sánchez-Coronilla, A.; Gallardo, J. J.; Hernández, N. C.; Piñero, J. C.; Alcántara, R.; Fernández-Lorenzo, C.; De los Santos, D. M.; Aguilar, T.; Martín-Calleja, J. New Insights Into Organic-Inorganic Hybrid Perovskite $\mathrm{CH}_{3} \mathrm{NH}_{3} \mathrm{PbI}_{3}$ Nanoparticles. An Experimental and Theoretical Study of Doping in $\mathrm{Pb}^{2+}$ Sites With $\mathrm{Sn}^{2+}, \mathrm{Sr}^{2+}, \mathrm{Cd}^{2+}$ and $\mathrm{Ca}^{2+}$. Nanoscale 2015, 7, 6216-6229.

(41) El-Mellouhi, F.; Marzouk, A.; Bentria, E. T.; Rashkeev, S. N.; Kais, S.; Alharbi, F. H. Hydrogen Bonding and Stability of Hybrid Organic-Inorganic Perovskites. ChemSusChem 2016, 9, 2648-2655.

(42) Zhang, Y. K.; Yang, W. T. Comment on "Generalized Gradient Approximation Made Simple". Phys. Rev. Lett. 1998, 80, 890.

(43) Dion, M.; Rydberg, H.; Schröder, E.; Langreth, D. C.; Lundqvist, B. I. van der Waals Density Functional for General Geometries. Phys. Rev. Lett. 2004, 92, 246401.

(44) Kresse, G.; Hafner, J. Ab Initio Molecular Dynamics for Liquid Metals. Phys. Rev. B: Condens. Matter Mater. Phys. 1993, 47, 558-561.

(45) Kresse, G.; Hafner, J. Ab Initio Molecular-Dynamics Simulation of the Liquid-Metal-Amorphous-Semiconductor Transition in Germanium. Phys. Rev. B: Condens. Matter Mater. Phys. 1994, 49, 14251-14269.

(46) Kresse, G.; Furthmüller, J. Efficient Iterative Schemes for ab initio Total-Energy Calculations Using a Plane-Wave Basis Set. Phys. Rev. B: Condens. Matter Mater. Phys. 1996, 54, 11169-11186.

(47) Grimme, S. Semiempirical GGA-type Density Functional Constructed With a Long-Range Dispersion Correction. J. Comp. Chem. 2006, 27, 1787-1799.

(48) Grimme, S.; Antony, J.; Ehrlich, S.; Krieg, H. A Consistent and Accurate $a b$ initio Parametrization of Density Functional Dispersion Correction (DFT-D) for the 94 Elements H-Pu. J. Chem. Phys. 2010, 132, 154104-154119.

(49) Grimme, S.; Ehrlich, S.; Goerigk, L. Effect of the Damping Function in Dispersion Corrected Density Functional Theory. J. Comput. Chem. 2011, 32, 1456- 1465.

(50) Zalake, P.; Ghosh, S.; Narasimhan, S.; Thomas, G. DescriptorBased Rational Design of Two-Dimensional Self-Assembled Nanoarchitectures Stabilized by Hydrogen Bonds. Chem. Mater. 2017, 29, 71707182.

(51) Zeinalipour-Yazdi, C. D.; Hargreaves, J. S. J.; Catlow, C. R. A. DFT-D3 Study of Molecular $\mathrm{N}_{2}$ and $\mathrm{H}_{2}$ Activation on $\mathrm{Co}_{3} \mathrm{Mo}_{3} \mathrm{~N}$ Surfaces. J. Phys. Chem. C 2016, 120, 21390-21398.

(52) Sutton, C.; Risko, C.; Brédas, J. -L. Noncovalent Intermolecular Interactions in Organic Electronic Materials: Implications for the Molecular Packing vs Electronic Properties of Acenes. Chem. Mater. 2016, 28, 3 16.

(53) Kim, S. J.; Park, B.; Noh, S. H.; Yoon, H. S.; Oh, J.; Yoo, S.; Kang, K.; Han, B.; Jun, S. C. Carrier Scattering in Quasi-free Standing Graphene on Hexagonal Boron Nitride. Nanoscale 2017, 9, 15934-15944.

(54) Peralta, D.; Chaplais, G.; Simon-Masseron, A.; Barthelet, K.; Chizallet, C.; Quoineaud, A. -A.; Pirngruber, G. D. Comparison of the Behavior of Metal-Organic Frameworks and Zeolites for Hydrocarbon Separations. J. Am. Chem. Soc. 2012, 134, 8115-8126.

(55) Li, S. -S.; Ji, W. -X.; Hu, S. -J.; Zhang, C. -W.; Yan, S. -S. Effect of Amidogen Functionalization on Quantum Spin Hall Effect in $\mathrm{Bi} / \mathrm{Sb}$ Films. ACS Appl. Mater. Interfaces 2017, 9, 41443-41453. 
(56) Sorescu, D. C.; Byrd, E. F. C.; Rice, B. M.; Jordan, K. D. Assessing the Performances of Dispersion-Corrected Density Functional Methods for Predicting the Crystallographic Properties of High Nitrogen Energetic Salts. J. Chem. Theory Comput. 2014, 10, 4982-4994.

(57) Blöchl, P. E. Projector Augmented-Wave Method. Phys. Rev. B: Condens. Matter Mater. Phys. 1994, 50, 17953-17979.

(58) Kresse, G.; Joubert, D. From Ultrasoft Psuedopotentials to the Projector Augmented-Wave Method. Phys. Rev. B: Condens. Matter Mater. Phys. 1999, 59, 1758-1775.

(59) Davis, J. B. A.; Baletto, F.; Johnson, R. L. The Effect of Dispersion Correction on the Adsorption of $\mathrm{CO}$ on Metallic Nanoparticles. $J$. Phys. Chem. A 2015, 119, 9703-9709.

(60) Anisimov, V. I.; Zaanen, J.; Andersen, O. K. Band Theory and Mott Insulators - Hubbard-U Instead of Stoner-I. Phys. Rev. B: Condens. Matter Mater. Phys. 1991, 44, 943-954.

(61) Zhou, F.; Cococcioni, M.; Kang, K.; Ceder, C. The Li Intercalation Potential of $\mathrm{LiMPO}_{4}$ and $\mathrm{LiMSiO}_{4}$ Olivines with $\mathrm{M}=\mathrm{Fe}, \mathrm{Mn}, \mathrm{Co}, \mathrm{Ni}$. Electrochem. Commun. 2004, 6, 1144-1148.

(62) Gracia, J.; Munarriz, J.; Polo, V.; Sharpe, R.; Jiao, Y.; Niemantsverdriet, J. W. H.; Lim, T. Analysis of the Magnetic Entropy in Oxygen Reduction Reactions Catalysed by Manganite Perovskites. Chem CatChem 2017, 9, 3358-3363.

(63) Bader, R. F. W. A Quantum Theory of Molecular Structure and its Applications. Chem. Rev. 1991, 91, 893-928.

(64) Otero-de-la-Roza, A.; Johnson, E. R.; Luaña, V. CRITIC2: A Program for Real-space Analysis of Quantum Chemical Interactions in Solids. Comput. Phys. Commun. 2014, 185, 1007-1018.

(65) Momma, K; Izumi, F. VESTA 3 for Three-dimensional Visualization of Crystal, Volumetric and Morphology Data. J. Appl. Crystallogr. 2011, 44, 1272-1276.

(66) Contreras-García, J.; Yang, W.; Johnson, E. R. Analysis of Hydrogen-Bond Interaction Potentials from the Electron Density: Integration of Noncovalent Interaction Regions. J. Phys. Chem. A 2011, 115, 1298312990.

(67) Bohorquez, H. J.; Boyd, R. J. A Localized Detector for Atomic and Molecular Systems. Theor. Chem. Acc. 2010, 127, 393-400.

(68) Chaudret, R.; Contreras-Garcia, J.; Delcey, M.; Parisel, O.; Yang, W.; Piquemal, J. -P. Revisiting $\mathrm{H}_{2} \mathrm{O}$ Nucleation around $\mathrm{Au}^{+}$and $\mathrm{Hg}^{2+}$ : The Peculiar "Pseudo-Soft" Character of the Gold Cation. J. Chem. Theory Comput. 2014, 10, 1900-1909. 
For Table of Contents Only:

Building Fluorinated Hybrid Crystals: Understanding the Role of Noncovalent Interactions

Julen Munárriz, * Federico A. Rabuffetti, and Julia Contreras-García*

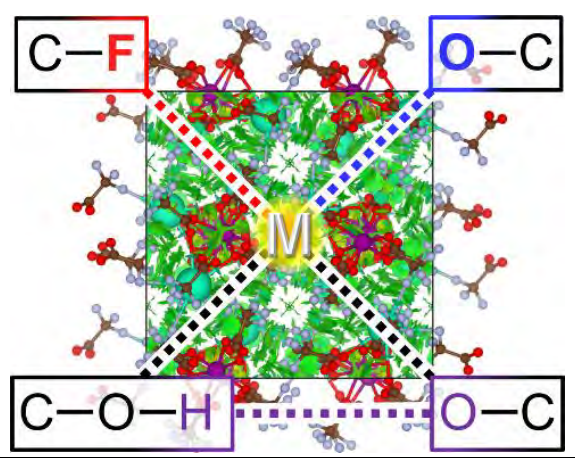

Noncovalent interactions in a series of organic-inorganic bimetallic fluorinated crystals were quantitatively mapped using a computational approach that combined NCI topological analysis, search of bond critical points, and a charge model. 